\title{
Conception of a hybrid pneumatic-combustion rotary vane engine - challenge and reality
}

\begin{abstract}
The paper presents a new concept of applying a rotary vane engine working as the hybrid system including both a combustion engine and a pneumatic motor, which were working simultaneously. In the beginning, review on both unconventional piston engine designs and similar like solutions on rotary vane engines were conducted. Next, description of the conceptual engine was presented. The concept was realized in practice. The prototype engine was built and it was preliminary investigated focusing on problems with cold start and misfiring events which occurred. The engine was tested on LPG and gasoline, however, its main target is to feed it with natural gas. This approach is justified as far as the engine finally might work in natural gas reduction stations and would provide electricity of $1 \mathrm{~kW}$ power for station's own demands.
\end{abstract}

Keywords: hybrid pneumatic-combustion engine, rotary engine

\section{Introduction}

The internal combustion engine as known as a machine which achieves its highest possible thermal efficiency among all the machinery converting chemical energy from a fuel into mechanical useful work resulted from the combustion process taken place inside an engine combustion chamber. As discussed by Lenz [1] future for means of transport drives belongs to internal combustion engines fueled with liquid fuels. Hence, the internal combustion engine is still attractive solution and effectively competitive to fuel cell drives as well as battery electric vehicles. As reviewed, the engine design has been evolving over centuries and currently the most popular is the reciprocating engine with piston joined to the crankshaft with aid of a connecting rod.

This engine design has been so well refined that it is now the basic type of thermal machine used as a drive in the means of transport as well as for generating electricity.

On the other hand, there are many engine designs that have not been implemented on a large industrial scale. However, from a certain point of view, they deserve recognition and are therefore also the subject of research in research centers and large automotive concerns.

Noteworthy is the construction of a rotary piston engine, whose prototype was the engine invented by Felix Wankel in 1926 and patented in 1936. Its production was discontinued many times and was again resumed, in which one can still discern the existing potential for the development of this engine type. Mazda has announced launching the Wankel-like engine into series production again. In 2013, Mazda created a prototype that incorporated a rotary range extender to increase range of a car up to $400 \mathrm{~km}$ in the car Mazda2 (Demio). The engine swept volume of 0.33-liter delivers 38 bhp that would be able to recharge onboard electric motor's batteries.

However, the Wankel engine is not the only type of unconventional solution for a reciprocating thermal machine. There are many different construction solutions. These solutions can be divided into several groups as follows:

- engine with a reciprocating piston,

- classic engine with a crank and a piston,
- engine with non-standard crank-piston assembly - rocker engine (Commer, Szymkowiak engine [2, 3]),

- barrel engine [4, 5],

- opposed piston engine without a shaft - free-piston engine integrated with a linear power generator [6],

- rotary engine - engine with rotational movement of the piston,

- a three-piston engine with its eccentric location - Wankel engine,

- a vane engine.

An interesting example of the unconventional engine design is the barrel engine by Mazuro et al. [2, 3] shown in Fig. 1d. They invented several useful solutions for charge exchange and reduce thermal stresses in the engine working on various alternative gases. Worth of noticing is the work by Zhang et al. [6]. They present a control strategy to improve the output power for a single-cylinder two-stroke free-piston linear generator (FPLG) as depicted in Fig. 1c. The piston motions, especially the dead center errors, are controlled by regulating the profile of the electromagnetic force. The results state that the proposed control strategy can improve the output power by around $7-10 \%$ with the same fuel cycle mass. ShokrollahIhassanbarough and the team [7] conducted simulation works on a 2-stroke opposed piston engine (Fig. 1c) and they provided several benefits which distinguish this engine over the classic 4-stroke reciprocating piston engine. As they stated, the current technology leveraging allows the opposed piston 2-stroke engine to be considered as an alternative for the conventional four-stroke engines as mechanical drive in various applications, mainly in transportation. In general, these engines are suited to compete with conventional 4-stroke engines where power-to-weight ratio, power-to-bulk volume ratio and fuel efficiency are requirements. Authors present a brief advent, as well as the renaissance of opposed-piston engines and the novel technologies which have been used in the new approach.

Figure 2 presents exemplary designs of rotary engines. As seen, the well-known design is the engine in Fig. 2a invented by Felix Wankel in 1926 and patented later in 1936. In 1797 Edmund Cartwright patented an engine 
a)

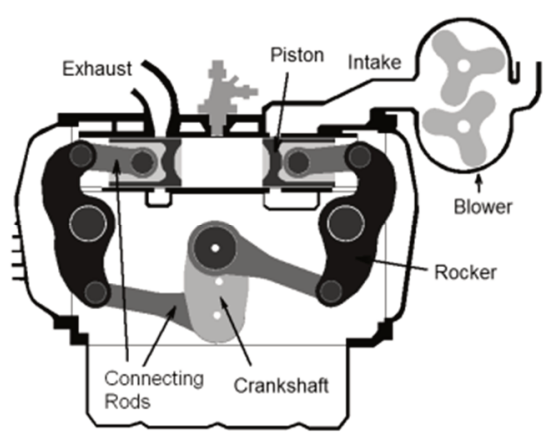

d)

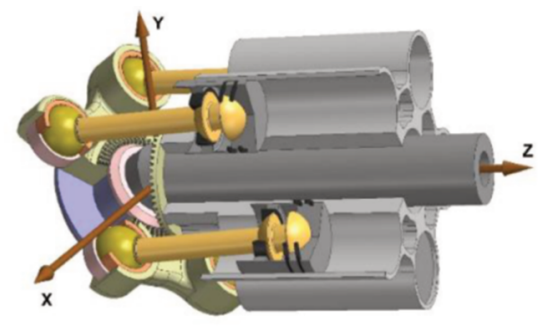

b)

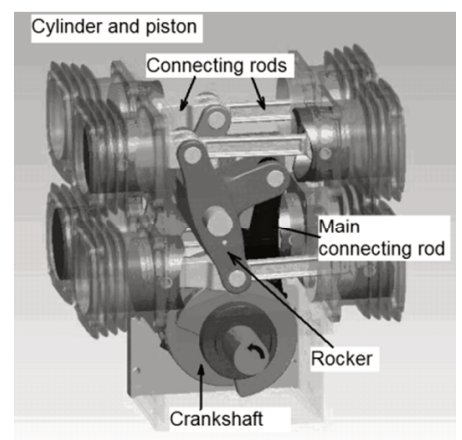

e)

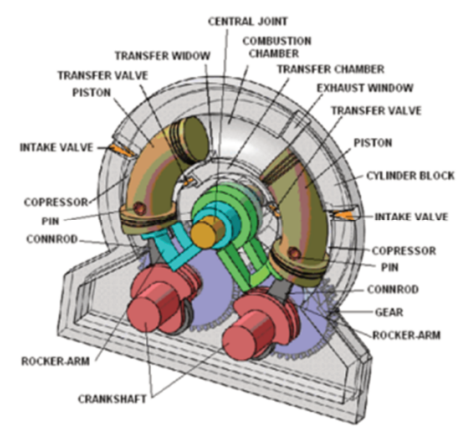

c)

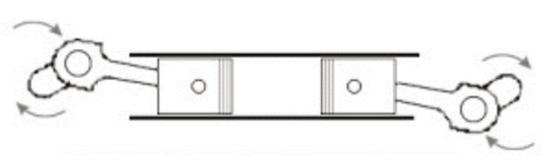

f)

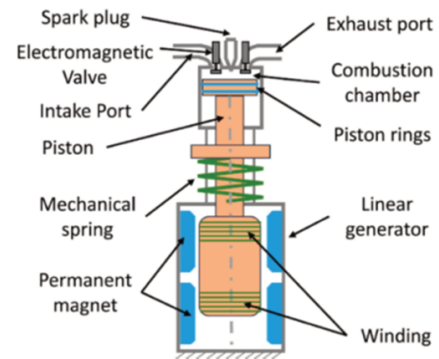

Fig. 1. Selected examples of various engine design: a) Commer rocker engine, b) Szymkowiak rocker engine [2, 3], c) principle of the opposed piston engine, d) barrel engine $[4,5]$, e) opposed engine - HOPE [8, 9], f) free piston engine [6]

a)

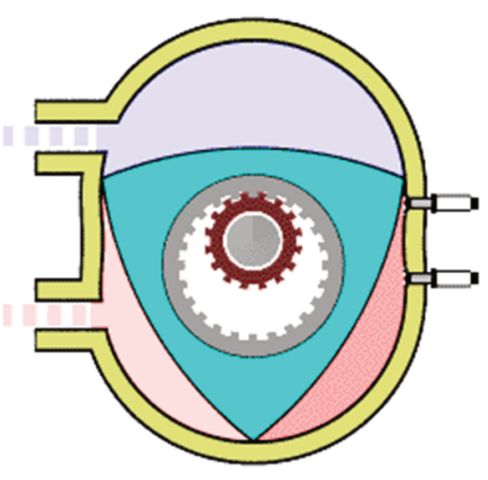

b)

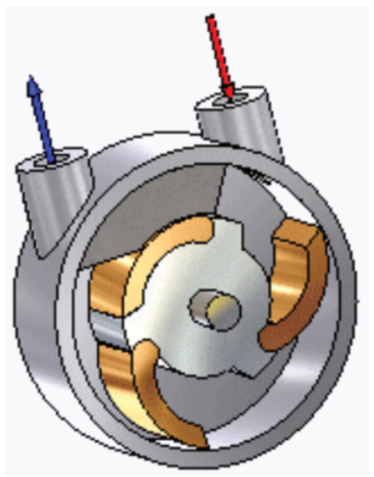

c)

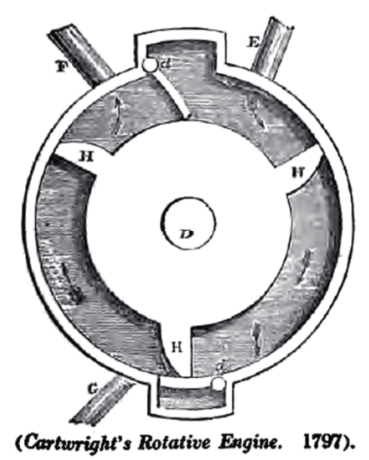

Fig. 2. Rotary engines: a) Wankel engine, b) rotary engine by J. Watt (1765) [10], c) rotary engine by E. Cartwright (1797) [10]

which was similar to Watt's 'abutment' engine, only with two flaps and three baffles working as pistons inside the rotating cylinder, as seen in Fig. $2 b, c$.

Coming back to main topic concerning rotary engines, as known, there are several pros and cons for these unconventional solutions in engine design. Among others, the most important are the following.

- The pros of rotary engines:

- Construction is relatively very simple. It contains a significantly lower number of parts as compared to the classical piston engine. Especially, the engine has moving parts in lower number. This makes them cost effective and lighter.

- Power to weight ratio is higher.

- Vibration generating by the engine is significantly lower due, because the engine does not contain any reciprocating motion.
- The cons of rotary engines:

- Lower overall efficiency. This is mainly because of both relatively low compression ratio and incomplete fuel combustion in the combustion chamber.

- Moreover, it causes higher toxic emission, particularly $\mathrm{UHC}$ and $\mathrm{CO}$ are significantly higher than in the classic IC engine.

- Lubricating oil leaking and higher oil consumption due to burning it in the combustion chamber. By design, the rotary engine burns oil because amounts of oil for lubricating the combustion chamber sealing remain there and mix with the fuel.

- High costs of repairs - as rotary engines are not very common, thus, the car service is not equipped with required tools as well is not experienced enough to provide effective repairs or even simple maintenance. which makes them expensive to repair. 


\section{Conception, construction and operation principle}

The machine was worked out on the basis of the patent No. PL 208394 [11] by K. Rzadkosz. It characterizes itself with the potential applications as follows:

- the machine can be used as a combustion engine with a high drive torque, which gives the possibility of using such an engine as a starter for large stationary gas engines and marine engines,

- as a pneumatic rotary actuator with high torque,

- as a pneumatic motor working at middle pressure natural gas stations,

- the machine can be used in a hybrid system working alternately as an internal combustion engine and as a pneumatic motor,

- the machine can be used as a high-performance compressor.

The essence of the originality of the construction that distinguishes it from the known designs of vane motors is the way of guiding the baffles which separate the chambers in the cylinder from the each other. The advantage of the presented way of guiding the baffles is the slight pressure affecting the cylinder's surface, which should significantly improve the service life of the baffles and at the same time ensure the tightness between the chambers.

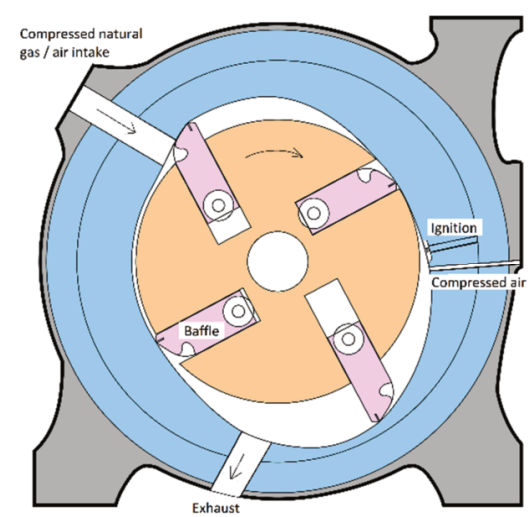

Fig. 3. Cross-section of the vane engine by K.Rzadkosz [11]

The engine resembles a classic vane motor used in pneumatic drive systems. The rotor has 4 baffles that define and simultaneously separate the adjacent chambers from each other. The rotor with baffles rotates inside the body (cylinder) constructed in such a way as to isolate from each other the following spaces: the part in which compression takes place, the part in which the ignition occurs and the part in which the gases are subject to expansion. In this mode of operation, it is the engine that works as an internal combustion engine and partially resembles the Wankel engine with a rotating piston, however, this piston is not located eccentrically.

A special feature of the engine is the baffle mounting system that adheres to the cylindrical surface to seal the adjacent motor chambers against each other. In order to reduce the force from the baffles pushing on the cylindrical surface, the author's method of guiding the baffles and reducing this force was developed, which directly affects the smaller friction losses and the lower wear of the cylinder liner and baffles.
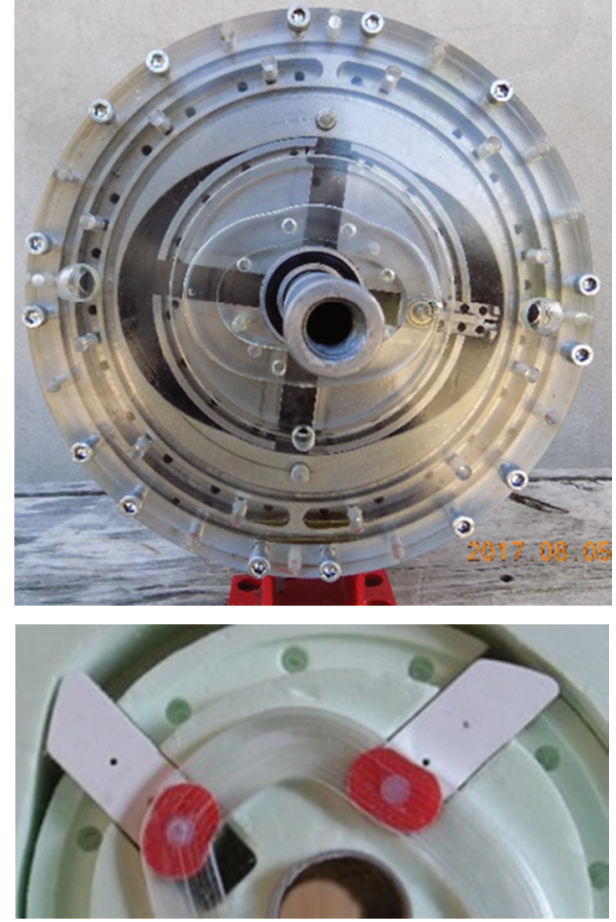

Fig. 4. a) Prototype of the vane engine by K. Rzadkosz, b) mechanism for guiding baffles in the engine

Another special feature of the engine is the use of an asymmetrical cylindrical body, which results in a smaller compression chamber and a larger expansion chamber. This solution leads to increase in engine efficiency, which results directly from applying so-called overexpanded thermodynamic cycle to the engine.

In the case of engine operation in hybrid mode, the engine will work alternately with combustion and pneumatic cycles as presented in Table 1, in contrast to commonly used separate exhaust and pneumatic systems.

Table 1. Working conditions for the vane engine

\begin{tabular}{|l|l|}
\hline Operation Mode & Work order - Chamber No. \\
\hline Combustion engine & $1,2,3,4$ CNG Combustion \\
\hline Alternate work & 1,3 Air Expansion \\
& 2,4 CNG Combustion \\
& or \\
& 1,2 Air Expansion \\
& or CNG Combustion \\
& every second cycle: \\
& $1,2,3,4$ Air Expansion \\
& $1,2,3,4$ CNG Combustion \\
& $1,2,3,4$ Air Expansion \\
\hline Pneumatic motor &
\end{tabular}

For example, the engine is supplied with compressed air at a pressure of approximately $30 \mathrm{bar}$. The expansion takes place at the bottom part of the engine (Fig. 3), whereas, the chamber located in the upper part sucks air and mixes it with natural gas injected into the inlet channel of the engine. The combustion process is initiated by a spark discharge. As mentioned, the fuel is CNG. Expansion of the exhaust gases takes place in the same part of the engine as the air expansion is done. 


\section{Potential benefits}

One can expect the following parameters to be improved:

- increasing the engine torque of the air motor with unchanged air flow - which results from the fact that the engine operates in every second cycle as a combustion engine,

- raising the efficiency of the air motor - this is due to the fact that alternating operation of the engine in combustion and pneumatic modes leads to increase in the average temperature of the pneumatic motor, and thus improvement in the expansion of the pneumatic medium (optionally natural gas or air) is observed.

- increase in the efficiency of the internal combustion engine compared to the rotary piston engine (Wankel engine). Due to alternative pneumatic-combustion operation, the average engine temperature is lower compared to the mean body temperature of the internal combustion engine, because expansion work in pneumatic mode causes additional cooling effect due to air / gas decompression. Such cooling effect of the engine will not significantly reduce its temperature, but this decrease is expected.

- improvement in engine efficiency in the hybrid system (gas-pneumatic) results from the overexpansion of the exhaust gases. The expansion stroke is longer as compared to the ratio of the compression stroke.

- as a result of lower temperature of the exhaust gases, the temperature of the elements sealing the combustion chamber will be reduced, which should partly eliminate the defects characteristic for the Wankel engine and thus improve the sealing system of the engine. The reduction of the average engine temperature is also important in determining the technological clearances required to provide dilatation as a result of the increase of the engine temperature from the cold start temperature to its operating temperature.

- low emission of toxic exhaust components will mainly concern nitrogen oxides whose emission strongly depends on the maximum combustion temperature.
Unfortunately, increase in $\mathrm{HC}$ emission resulting from the need to lubricate the cylinder liner is expected, but this is a problem commonly found in this type of construction.

\section{Preliminary investigation}

The engine was constructed and preliminary tested at the domestic test bed consisted of the dynometer and a speed indicator as depicted in Fig. 5a,b. The dynometer was built from the 3-phase asynchronous motor with nominal power of $1.5 \mathrm{~kW}$.

The technical specifications of the engine are the following:

- Fuel: LPG/gasoline, ether,

- Swept volume of a single combustion chamber: $40 \mathrm{~cm}^{3}$,

- No. of chambers: 4 ,

- No. of combustion events per one rotation: 4,

- Ignition system: spark discharge,

- Compression ratio: 8 ,

- Expansion ratio: 11.5,

- Rotational speed range: $650 \ldots 800 \mathrm{rpm}$.

The engine used to work for several minutes either gasoline or LPG as fuels. The problem occurred with high misfiring events expressed by COV over $20 \%$. The problem was probably supposed by a spark timing actuator working not effective enough with the crank encoder. However, cold start of the engine might also be a cause, as far as the engine combustion chamber in its top dead centre is in shape of elongated gap.

\section{Conclusion}

The vane engine was constructed and investigated preliminary at cold start conditions. The engine misfiring events occurred at work. Hence, further work on improving a spark system, as well as start of combustion is realized. On the other hand, one can state, that first attempts on starting the engine were successful, even though these problems reported.

On the basis of fundamental considerations, the following remarks, advantages and essential features were found as follows: a)

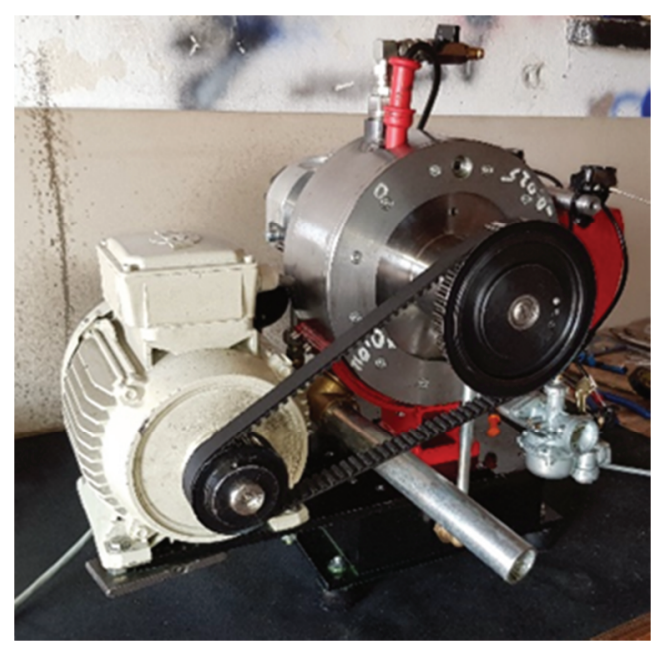

b)

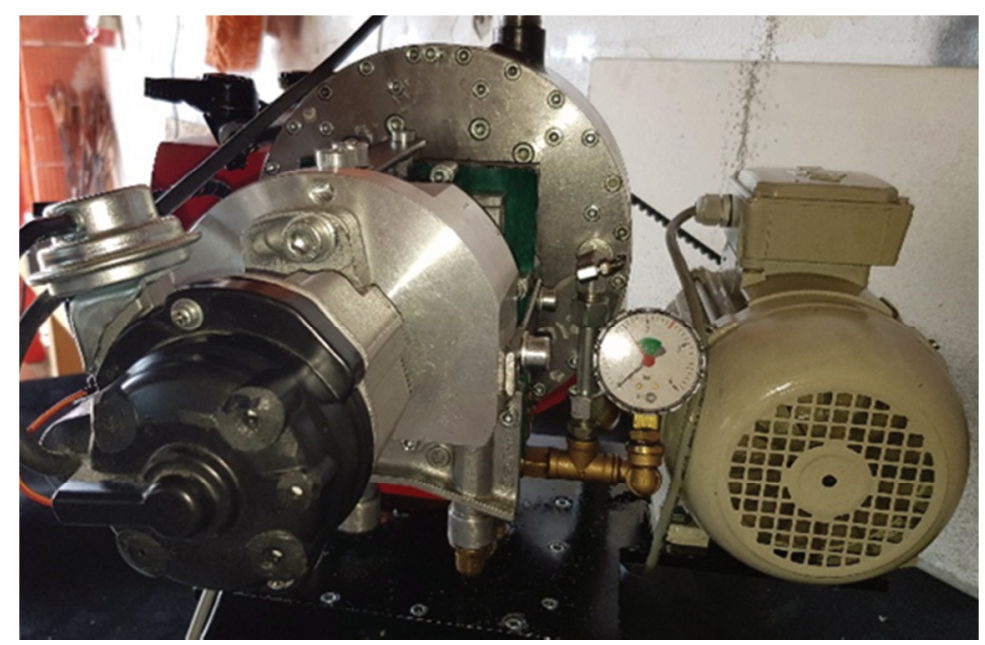

Fig. 5. Test bed of the vane engine by K. Rzadkosz 
- the engine can be easily adopted to work with the overexpanded cycle,

- due to alternative work consisted of: expansion of pressurized air and combustion events, removal of the exhaust gases residuals from the combustion chamber before the next burning cycle can be achieved,

- potential for downsizing - small dimensions at high performance - for example: the vane engine with two rotors with a cubic capacity of a single chamber of 500 $\mathrm{cm}^{3}$ are equivalent in terms of mechanical power to a 16-cylinder piston engine of 8 liters (of course assuming the same general efficiency of the engine) with a nominal power of $120 \mathrm{~kW}$. It has been taken into ac-

count that such engine will not be overloaded in order to obtain its better durability and reliability,

- the vane engine can work as the source for a system for compressed air and electricity of $400 \mathrm{~V} / 32$ A with output power up to $20 \mathrm{~kW}$. It will be possible to secure repair workshops in field conditions.

\section{Acknowledgement}

This project has partially received funding from the European Union's Horizon 2020 research and innovation programme under grant agreement No. 691232 - Knocky H2020-MSCA-RISE-2015.

\section{Bibliography}

[1] LENZ, H.P. Future mobility without internal combustion engines and fuels?. Combustion Engines. 2013, 155(4), 3-15.

[2] KOZAK, W. Crank and rocker piston assembly. Combustion Engines. 2013 152(1).

[3] SZYMKOWIAK, M., SZWAJA, S. New concept of a rocker engine - kinematic analysis. Journal of Kones - Powertrain and Transport. 2012, 19(3), 443-450.

[4] PYSZCZEK, R., MAZURO, P., JACH, A., TEODORCZYK, A. Numerical investigation on low calorific syngas combustion in the opposed-piston engine. Combustion Engines. 2017, 169(2), 53-63. DOI: 10.19206/CE-2017-210.

[5] KALKE, J., MAZURO, P., SULIKOWSKI, P. Development of the numerical scavenging process analysis in opposedpiston engines. Combustion Engines. 2015, 162(3), 511-519.

Stanisław Szwaja, DSc., DEng. - Faculty of Mechanical Engineering and Computer Science, Częstochowa University of Technology.

e-mail:Szwaja@imc.pcz.pl
[6] ZHANG, C., CHEN, F., LI, L. et al. A free-piston linear generator control strategy for improving output power. Energies. 2018, 11(135). DOI:10.3390/en11010135.

[7] SHOKROLLAHIHASSANBAROUGH, F., ALQAHTANI, A., WYSZYNSKI, M.L. Thermodynamic simulation comparison of opposed two-stroke and conventional four-stroke engines. Combustion Engines. 2015, 162(3), 78-84.

[8] contest.techbriefs.com/2013/entries/sustainabletechnologies $/ 3317$

[9] www.hybrid-engine-hope.com/hope-two_stroke_engine

[11] www.douglas-self.com/MUSEUM/POWER/rotaryengines/ rotaryeng.htm\#watt

[12] RZADKOSZ, K. Silnik z wirującym tłokiem. Patent nr PL 208394.
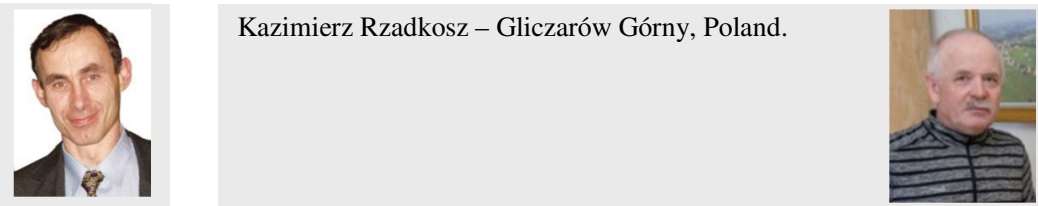